\title{
Sistem Mikrokontroler Untuk Menentukan Kualitas Air Yang Dapat di Gunakan Oleh Konsumen dengan Menggunakan Arduino
}

\author{
Fahri Rahmadani ${ }^{1}$, Suhada ${ }^{2}$, Bahrudi Efendi Damanik ${ }^{3 *}$ \\ Program Studi Teknik Informatika, STIKOM Tunas Bangsa, Pematangsiantar, Indonesia \\ Email: 1fachriramadhani27@gmail.com, 2suhada@amiktunasbangsa.ac.id,3,"bahrudiefndi@ gmail.com
}

\begin{abstract}
Abstrak-Usaha yang menyediakan air minum isi ulang saat ini telah banyak ditemui disetiap kota - kota besar, karena selain harga yang tidak terlalu mahal dapat mempersingkat waktu karena tidak perlu kesulitan dalam memperoleh air bersih. Pemilik usaha air minum isi ulang masih belum mengetahui apakah air yang di produksi apakah sudah layak untuk dikonsumsi. Oleh karena itu akan dibuat alat untuk mengukur kualitas air berdasarkan parameter yang dipilih yaitu nilai $\mathrm{pH}$ air dengan menggunakan sensor $\mathrm{pH}$ meter berbasir arduino Uno dan ditampilkan melalui layar $L C D$ agar dapat melihat langsung hasil pengujian air isi ulang tersebut.
\end{abstract}

Kata Kunci: Air Minum Isi Ulang; pH Meter Sensor; Arduino Uno

Abstract-There are now many businesses that provide refilled drinking water in every big city, because besides that, the price that is not too expensive can save time because there is no need for difficulties in obtaining clean water. The owner of the drinking water business still does not know whether the water produced is fit for consumption. Therefore, a tool will be made to measure air quality based on the selected parameter, namely the $\mathrm{pH}$ value of the water by using a $\mathrm{pH}$ meter sensor based on Arduino Uno and displayed through an LCD screen so that you can see directly the results of the refilled water test.

Keywords: Refill Drinking Water; pH Meter Sensor; Arduino Uno

\section{PENDAHULUAN}

Di era yang serba maju seperti sekarang ini telah banyak teknologi yang diciptakan oleh manusia untuk mempermudah pekerjaan, salah teknologi tersebut adalah Mikrokontroler. Mikrokontroler merupakan sebuah chip yang berupa (Integrated Circuit) yang didalamnya terdiri dari komponen utama berupa resistor, transistor dan komponen pendukung lainnya. Mikrokontroler mempunyai fungsi yaitu menerima sinyal input kemudian mengolah sinyal tersebut dan mampu memberikan sinyal output sesuai dengan program yang di masukkan kedalamnya[1], [2]. Secara ringkas Mikrokontroler bisa diartikan sebagai sistem pengendali kecil yang dapat bekerja apabila telah sinkron dengan code program yang akan dibuat. Jenis Mikrokontroler yang saat ini populer dan banyak digunakan adalah Arduino, sebab arduino mempunyai kelebihan diantaranya merupakan platform terbuka yang dapat digunakan oleh siapa saja biasa disebut dengan open source serta memiliki kemiripan syntaks dengan bahasa pemrograman c. Air merupakan elemen yang sangat penting bagi makhluk hidup, khususnya umat manusia karena sangat di perlukan untuk melakukan berbagai aktivitas dalam kehidupan sehari - hari seperti memasak, mencuci, menyiram tanaman, sarana rekreasi keluarga, sebagai pembangkit listrik tenaga air (PLTA) dan sebagainya[3]. Air dapat dinyatakan layak untuk dikonsumsi adalah air yang telah melalui proses pengolahan sesuai dengan standard kriteria mutu air. Kebutuhan air bersih untuk dikonsumsi harus selalu menjadi bahan pertimbangan bagi kesehatan masyarakat. Air yang mempunyai kualitas yang baik ditandai dengan $\mathrm{pH}$ air standard berkisar antara 7,8 - 8,5 [4].

Saat ini sudah banyak usaha yang menyediakan air minum isi ulang, biasa disebut dengan depot. Keberadaan depot air minum isi ulang sangat membantu masyarakat dalam menyediakan kebutuhan air minum karena sifatnya yang tidak banyak menghabiskan waktu, cukup dengan memesan air minum isi ulang tanpa perlu memasak air terlebih dahulu. Pada umumnya sistem yang digunakan oleh depot air minum isi ulang masih menggunakan teknologi filter sederhana yaitu dengan menggunakan sistem penyaringan lalu air dimasukkan kedalam galon, sehingga pihak dari usaha depot air minum tersebut kesulitan untuk melihat apakah kualitas air yang di produksi sudah benar - benar aman untuk dikonsumsi oleh konsumen[5].

Atas permasalahan tersebut penulis akan membuat suatu sistem mikrokontroler berbasis arduino untuk menentukan kualitas air berdasarkan parameter yang akan diuji pada depot air minum isi ulang yaitu nilai $\mathrm{pH}$, sebagai solusi bagi pemilik usaha depot air minum ulang untuk melihat secara langsung apakah air tersebut sudah layak untuk di konsumsi bagi konsumen.

\section{METODOLOGI PENELITIAN}

\subsection{Tahapan Penelitian}

Penelitian ini akan membahas tentang perancangan alat untuk menentukan kualitas air berdasarkan parameter yang akan diuji yaitu nilai $\mathrm{pH}$ air dengan menggunakan arduino uno. Pada tahap perancangan alat ini meliputi perangkat keras dan perangkat lunak [6]. Dalam penelitian ini akan dijelaskan alur dari proses percobaan hingga selesai melalui flowchart 1. dibawah ini[7]. 


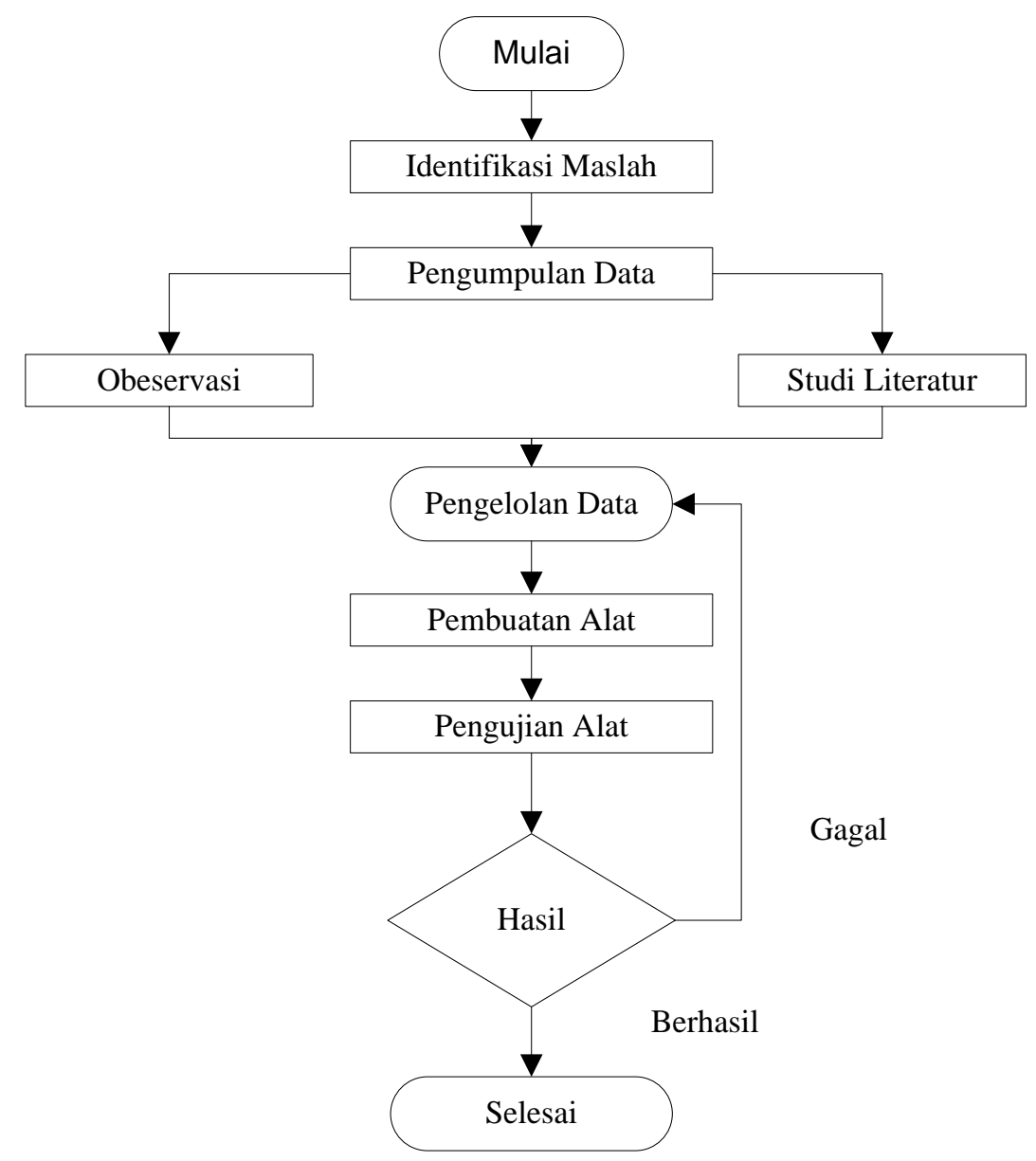

Gambar 1. Tahapan Penelitian

Flowchart penelitian yang telah dibuat akan dijelaskan sebagai berikut:

a) Identifikasi Masalah

Permasalahan pada penelitian ini yaitu pihak depot belum bisa mengetahui secara pasti apakah air yang mereka produksi untuk konsumen sudah benar sesuai dengan standard baku mutu air.

b) Pengumpulan Data

Data dari proses penelitian ini di dapat langsung dari depot Maharani Water dengan bentuk sampel air depot untuk dijadikan bahan pengujian berdasarkan parameter yang diuji yaitu nilai $\mathrm{pH}$ air.

c) Pengolahan Data

Pada tahap ini data telah di dapat dari studi identifikasi masalah dan pengumpulan data yang kemudian akan di olah untuk menyelesaikan permasalahan yang ada.

d) Studi Literatur

Metode pengumpulan data dengan menggunakan buku elektronik, buku pustaka dan jurnal yang terkait sebagai referensi bagi penelitian ini.

e) Observasi

Metode pengumpulan data dengan cara mengambil sampel air yang akan diuji dengan cara meminta izin kepada pemilik depot air minum.

f) Pembuatan Alat

Untuk menyelesaikan permasalahan pada penelitian ini, peneliti akan membuat sebuah alat dari tahap awal hingga ke tahap akhir.

g) Pengujian Alat

Melakukan pengujian alat kemudian menguji nilai $\mathrm{pH}$ air.

h) Hasil

Menghasilkan alat yang mampu menguji nilai $\mathrm{pH}$ air dengan keakuratan yang baik. Output yang dihasilkan dari alat ini akan tampil melalui $1 \mathrm{CD}$.

\subsection{Prosedur Pengumpulan Data}

Di tahap ini peneliti menjelaskan tujuan dari penelitian yang akan dilakukan yaitu untuk membantu pihak depot untuk menentukan kualitas air berdasarkan nilai $\mathrm{pH}$ air, kemudian dilanjutkan dengan meminta izin untuk mengambil sampel air yang akan diuji[8]. 


\subsection{Kebutuhan Perangkat}

Untuk melakukan perancangan alat untuk menentukan kualitas air berdasarkan parameter yang akan diuji $\mathrm{pH}$ dan tingkat kekeruhan air, maka diperlukan teknik analisis deskriptif yang penyajian datanya bersumber dari perangkat keras dan perangkat lunak dapat dilihat sebagai berikut [9]:

a) Perangkat Keras (Hardware)

Instrumen dan komponen elektronika untuk pembuatan alat untuk menentukan kualitas air berdasarkan parameter yang akan uji $\mathrm{pH}$ dan tingkat kekeruhan air dapat dilihat pada tabel 1 dibawah ini[10]:

Tabel 1. Perangkat Keras Penelitian

\begin{tabular}{cc}
\hline No. & Nomor \\
\hline 1 & Adaptor 12V DC \\
2 & Arduino Uno Atmega 328p \\
3 & Ph meter sensor \\
4 & Kabel Jumper \\
5 & LCD \\
6 & Buzzer \\
\hline
\end{tabular}

b) Perangkat Lunak (Software)

Pada perancangan perangkat lunak merupakan langkah membuat code program yang sesuai dengan algoritma untuk memasukkan program pada arduino uno agar setiap komponen elektronik dapat bekerja sesuai dengan sistem yang akan di bangun. Perangkat Lunak (Software) yang digunakan adalah Arduino IDE.

\section{HASIL DAN PEMBAHASAN}

Dalam hal ini penulis akan melakukan analisis dan pembuatan alat yang digunakan untuk proses input dan output. Deskripsi kerja alat secara keseluruhan dari sistem yang akan dibuat pada penelitian ini, sistem ini akan mulai beroperasi ketika board arduino diberikan sumber tegangan listrik, sumber arus listrik yang digunakan adalah adaptor dengan arus sebesar 12V DC. Kemudian input akan didapatkan dari sensor pHmeter yang berfungsi mengirimkan data ke board arduino dengan cara menguji alat tersebut apakah bekerja sesuai dengan perintah yang dimasukkan kedalam arduino, setelah itu untuk menampilkan hasil dari pengujian akan ditampilkan melalui LCD[11].

\subsection{Blok Diagram}

Rancangan blok diagram dapat dilihat pada gambar 2 dibawah ini[12].

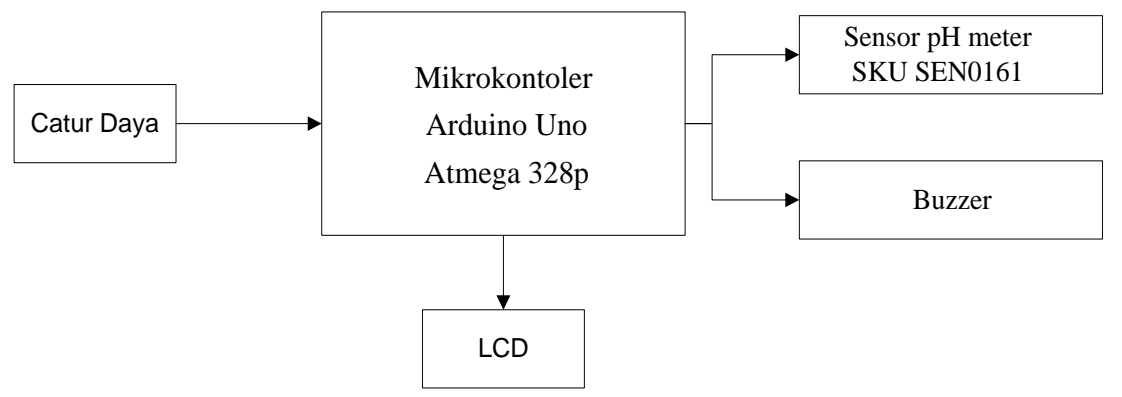

Gambar 2. Blog Diagram

Pada blog diagram 2. diatas terdapat beberapa komponen perangkat keras yang mempunyai fungsi sebagai berikut:

a) Catu Daya merupakan komponen yang berfungsi untuk memberikan arus listrik ke semua rangkaian yang terpasang dalam alat tersebut.

b) Mikrokontroler arduino uno Atmega 328p yang berfungsi sebagai pengendali untuk sensor sensor yang digunakan.

c) Sensor pH SKU SEN0161 mempunyai fungsi untuk mendeteksi nilai dari derajat keasaman lalu dikonversi ke dalam nilai $\mathrm{pH}$.

d) LCD merupakan komponen yang digunakan untuk menampilkan nilai $\mathrm{pH}$ dari hasil dari pengujian.

e) Buzzer merupakan komponen yang digunakan untuk memberikan alat keluaran berupa bunyi.

\subsection{Diagram Rancangan Alat}

Sebelum prosedur kerja arduino uno $R 3$, terlebih dahulu penulis akan menguraikan hasil dari rancangan dalam pembuatan alat yang dapat mengukur kualitas air berdasarkan parameter yang diuji adalah nilai $p H$ dengan menggunakan arduino. Proses perakitan merupakan proses penggabungan antara mikrokontroller arduino R3, pH meter sensor SKUSEN0161, LCD (Liquid Crystal Display), jumper wire, buzzer dan beberapa komponen pendukung lainnya untuk menyelesaikan alat tersebut. Skema rangkaian dapat dilihat pada gambar 3 dibawah ini: 


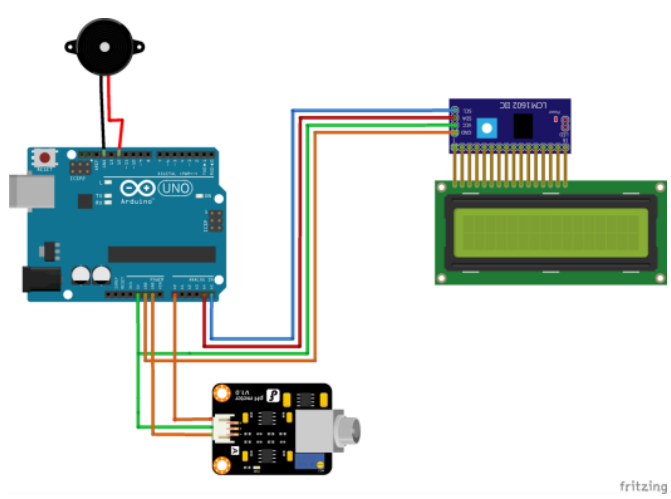

Gambar 3. Skema Rangkaian Keseluruhan

Pada gambar 3 diatas dapat dilihat skema rangkaian keseluruhan arduino uno $R 3$ dan sensor lainnya serta menghubungkan setiap pin pada modul yang akan di letakkan pada board arduino uno R3 tersebut. Koneksi antar pin dapat dilihat sebagai berikut:

a) Pin VCC pada LCD dihubungkan ke $5 \mathrm{~V}$ arduino.

b) Pin GND pada LCD dihubungkan ke GND arduino.

c) Pin SDA pada LCD dihubungkan ke A4 arduino.

d) Pin SCL pada LCD dihubungkan ke A5 arduino.

e) Pin + pada buzzer dihubungkan ke 5V arduino.

f) Pin - pada buzzer dihubungkan ke 12 arduino.

g) Pin - pada $\mathrm{pH}$ meter sensor dihubungkan ke GND arduino.

h) Pin + pada $\mathrm{pH}$ meter sensor dihubungkan ke $5 \mathrm{~V}$ arduino.

i) Pin Input pada $\mathrm{pH}$ meter sensor dihubungkan ke A0 arduino.

Setelah pin pada setiap modul telah terhubung sesuai dengan tempatnya selanjutnya yaitu memasukkan program kedalam rangkaian arduino uno $R 3$ secara keseluruhan, dengan menggunakan software Arduino IDE. Sehingga rangkaian dapat bekerja sesuai dengan apa yang penulis rencanakan sebelumnya.

Dalam pembuatan alat untuk menentukan kualitas air yang dapat digunakan oleh konsumen berdasarkan parameter yang diuji adalah nilai $p H$ dengan menggunakan arduino uno $R 3$ di Maharani Water yang beralamat di jalan Rakuta Sembiring kota pematangsiantar dibutuhkan beberapa komponen dan peralatan pendukung untuk memudahkan proses perakitan dari awal hingga selesai. Beberapa komponen dan peralatan pendukung dapat dilihat pada tabel 4.2. dibawah ini:

Tabel 2. Spesifikasi Kebutuhan Sistem

\begin{tabular}{ccccc}
\hline No & Komponen & Jumlah & Peralatan & Jumlah \\
\hline 1 & Arduino Uno R3 & 1 & BOR & 1 \\
2 & pH meter sensor & 1 & & \\
3 & Buzzer & 1 & Solder & 1 \\
4 & LCD 16x2 & 1 & Lem alteco & 1 \\
5 & Kabel Jumper & 25 & Lem silicon & 1 \\
6 & Kaca & $50 \times 50 \mathrm{~cm}$ & Lem silicon & 1 \\
7 & Alumunium & $2 \mathrm{~m}$ & Lem silicon & 6 \\
\hline
\end{tabular}

\subsubsection{Masukan (Input)}

Dalam perancangan perangkat lunak pada program mikrokontroller arduino uno $R 3$ menggunakan software arduino $I D E$ yang memiliki kesamaan syntaks dengan bahasa pemrograman $C++$ serta memiliki fitur yang dapat mempermudah yaitu library yang berfungsi untuk menulis program ke dalam board arduino. Setelah merancang alat untuk menentukan kualitas air berdasarkan parameter yang diuji yaitu nilai $p H$, penulis akan memasukkan perintah kedalam board mikrokontoller arduino $R 3$ sesuai dengan alat yang dibuat penulis, Untuk memasukkan program ke dalam board arduino dibutuhkan sebuah driver USB, Arduino IDE, dan sebuah Board Arduino Uno R3.

Untuk Input data utama pada komponen alat yang dibuat penulis adalah $p H$ meter sensor SKUSENO161 untuk memberitahukan nilai $\mathrm{pH}$ yang ada pada air agar arduino dapat memproses data yang akan dikirim sebagai output. Penampakan $p H$ meter sensor SKUSEN0161 yang telah terpasang pada rangkaian.

\subsubsection{Pemrosesan (Processed)}

Data yang diterima dari pH meter SKUSEN0161 kemudian akan di susun dan diproses oleh mikrokontroller arduino uno R3. Data yang didapat dari hasil sensor tersebut akan diproses oleh board arduino uno $R 3$ dan arduino yang telah berisi program akan memerintahkan $p H$ meter sensor SKUSENO161 untuk melakukan pengukuran nilai $p H$ pada 
air,kemudian jika pH normal bernilai 7 buzzer akan berbunyi menandakan air tersebut layak untuk dikonsumsi dan jika nilai $\mathrm{pH}$ air $<7$ atau $>7$ tidak akan berbunyi.

\subsubsection{Keluaran (Output)}

Dalam pembuatan alat untuk menentukan kualitas air yang dapat digunakan oleh konsumen berdasarkan parameter yang akan diuji yaitu nilai $p H$ dengan menggunakan arduino uno R3 dengan pH meter sensor SKU SENO161 penulis menambahkan komponen tambahan berupa alat keluaran (output) LCD (Liquid Crystal Display) yang berfungsi untuk mengetahui nilai $\mathrm{pH}$ pada air yang diuji.

\subsection{Prototyping Rangkaian}

Pada tahap ini alat yang sudah dirancang selanjutnya akan melalui tahap prototyping dan simulasi. Alat ini akan mendeteksi nilai dari $p H$ pada air secara otomatis dimana $p H$ air yang bernilai $>7$ bersifat asam, $>7$ bersifat basa dan pH yang bernilai 7 adalah normal. Nilai pH yang terdeteksi akan ditampilkan melalui LCD (Liquid Crystal Display) lalu buzzer akan berbunyi jika $p H$ air normal, jika $p H$ air tidak normal maka buzzer tidak akan berbunyi. Selanjutnya penulis akan menguraikan beberapa tahapan manfaat dari alat yang telah selesai dibuat. Hasil dari perancangan alat dimulai dari input sensor, proses dan output. Dan hasil akhir dari alat yang telah dibuat dapat dilihat pada gambar 3. dibawah ini:

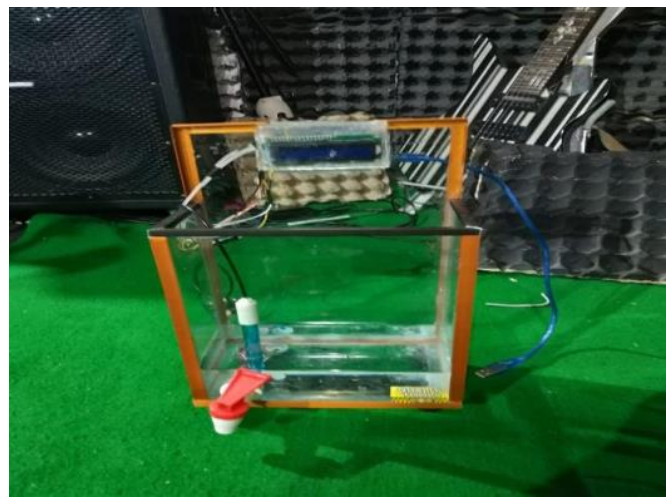

Gambar 3. Hasil Alat

\subsection{Prosedur Pengujian Alat}

Pada tahapan awal pengujian sistem ini adalah dengan memberikan daya sebesar 12volt ke dalam board arduino kemudian modul pH meter sensor SKUSEN0161 akan merespon pembacaan kurang lebih 1 menit, ini berguna untuk memeriksa apakah sensor dalam keadaan mati atau hidup. kemudian sensor akan melakukan validasi dan membaca data, data kemudian langsung di proses ke dalam board arduino lalu akan ditampikan pada layar $L C D$. Jika terjadi kesalahan pada modul sensor maka layar $L C D$ tidak akan menampilkan karakter apapun. Sebaliknya jika modul sensor telah melakukan pengukuran maka hasilnya akan di tampilkan pada layar $L C D$.

Setelah sistem siap maka sistem akan mulai membaca dan melakukan pengukuran nilai $\mathrm{pH}$ air, jika $\mathrm{pH}$ air normal bernilai 7 maka secara otomatis akan di tampilkan pada layar $L C D$, bersamaan dengan tampilnya output pada $L C D$ buzzer juga akan berbunyi, sebaliknya jika $\mathrm{pH}<7$ atau $>7$ buzzer tidak akan berbunyi.

\section{KESIMPULAN}

Berdasarkan hasil uraian dari pembahasan di atas, disimpulkan dengan adanya alat untuk menentukan kualitas air berdasarkan parameter yang dipilih adalah $\mathrm{pH}$ air diharapkan dapat memudahkan pihak depot air minum isi ulang dapat mengetahui apakah air yang di produksi sudah sesuai dengan standard baku mutu air. Alat tersebut dapat memberi rasa aman bagi masyarakat yang mengkonsumsi air depot minum isi ulang.

\section{REFERENCES}

[1] A. Putra, A. Indra, and H. Afriyastuti, "PROTOTIPE SISTEM IRIGASI OTOMATIS BERBASIS PANEL SURYA MENGGUNAKAN METODE PID DENGAN SISTEM MONITORING IoT,” Repository.Unib.Ac.Id, 2018.

[2] I. Mahdi and D. Kasoni, "Rancang Bangun Prototype Kelembaban Tanah," vol. V, no. 1, pp. 77-87, 2019.

[3] M. A. Wijaya, R. Hanifah, and M. C. T. Manullang, "Purwarupa penyiraman otomatis dengan arsitektur mqtt dan logika fuzzy sugeno untuk meningkatkan keefektifan manajemen penyiraman tanaman (studi kasus : itera)," J. Teknol. Inf. Univ. Lambung Mangkurat, vol. 05, no. 2, pp. 49-56, 2020.

[4] P. A. Wulandari, P. Rahima, and S. Hadi, "Rancang Bangun Sistem Penyiraman Otomatis Berbasis Internet of Things Pada Tanaman Hias Sirih Gading," J. Bumigora Inf. Technol., vol. 2, no. 2, pp. 77-85, 2020.

[5] P. Setiawan, E. Y. Anggraen, P. Studi, S. Informasi, and S. Kelembapan, "Prorotype Sistem Penyiraman Tanaman Otomatis Terjadwal dan Berbasis Sensor Kelembapan Tanah,” Ibi Darmajaya, pp. 277-283, 2019.

[6] V. C. Alverina, J. Siwalankerto, S. Jln, S. Surabaya, and J. Siwalankerto, "Aplikasi Monitoring Kesuburan Tanaman Hias Mawar 
Journal of Information System Research (JOSH)

Volume 2, No. 4, Juli 2021

ISSN 2686-228X (media online)

Hal: $254-259$

menggunakan Arduino."

[7] J. Tarigan and M. Bukit, "Rancang Bangun Sistem Penyiraman Tanaman Secara Mandiri Berbasis Mikrokontroller Atmega 8535," J. Fis. Fis. Sains dan Apl., vol. 3, no. 3, pp. 137-141, 2018.

[8] D. A. N. Iot and M. R. Fahroni, “mencapai derajat Sarjana S1 Disusun oleh : Jurusan Teknik Elektro Fakultas Teknologi Industri Universitas Islam Indonesia Yogyakarta," 2020.

[9] L. H. L. Ari Permana L, Sefnath J. Wattimena, "JURNAL PENGABDIAN MASYARAKAT IRON ( sipil , elektro , mesin )," J. Pengabdi. Masy. IRON (sipil, elektro, mesin), vol. 01, no. 01, pp. 24-29, 2018.

[10] Harifuzzumar, F. Arkan, and Ghiri Basuki Putra, "Perancangan Dan Impelementasi Alat Pemberian Pakan Ikan Lele Otomatis Pada Fase Pendederan Berbasis Arduino Dan Aplikasi Blynk," Pros. Semin. Nas. Penelit. Pengabdi. pada Masy., pp. 67-71, 2018.

[11] E. A. Suprayitno MT, R. D. M.Kom, and M. A. ST, "Otomasi Sistem Hidroponik DFT (Deep Flow Technique) Berbasis Arduino Android dengan Memanfaatkan Panel Surya sebagai Energi Alternatif,” Elinvo (Electronics, Informatics, Vocat. Educ., vol. 3, no. 2, pp. 30-37, 2019.

[12] C. Chotimah and K. P. Kartika, "Sistem Penyiraman Dan Pengusir Hama Otomatis Pada Daun Mint Berbasis Mikrokontroler Arduino Uno," Antivirus J. Ilm. Tek. Inform., vol. 13, no. 1, pp. 36-47, 2019. 